\title{
Estrus anorexia: Single-tube intake and barpress rate in the albino rat*
}

\author{
WILMAR A. JENNINGS† \\ Howard Lniversity, Washington, D.C. 20001
}

\begin{abstract}
An inhibition of the motivation to feed in estrus was found in albino rats with two different measures: 1-h intake from a single drinking tube, and barpress rate with an ascending FR schedule. A variety of liquid foods were used: sucrose, whole milk, nonfat milk, and lactose. All of the foods showed the inhibition associated with estrus; but the inhibition was not greater for less preferted than for morepreferred foods. The data support previous work showing that the estrous cycle modified the motivation for food considered as calories, but fail to provide evidence that the estrous cycle modified the palatability of foods differentially.
\end{abstract}

The well-documented reduction in food intake as the rat enters estrus is generally considered a reduction in the motivation to feed (Aschkenasy-Lelu \& Aschkenasy, 1959; Harris \& Heistad, 1970; Wade \& Zucker, 1970). If estrus inhibits the motivation to feed, such an inhibition should be evident in a variety of measures of hunger. Previous work with hypothalamic lesions (Miller, Bailey, \& Stevenson, 1950) taught an important lesson: Different measures of hunger bear different relations with the same independent variable.

A similar situation may exist in the case of the estrous cycle as a variable affecting hunger. For example, the results of previous studies concerned with the rate of instrumental responding for food are inconsistent. Hodos and Valenstein (1960) found that estrus (induced in ovariectomized rats with estrogen and progesterone) did not affect the rate of barpressing for milk with a VI 30-sec schedule of reinforcement. In contrast, Harris and Heistad (1970) demonstrated that both natural estrus and estrogen replacement in ovariectomized rats inhibited the rate of barpressing for stock diet pellets with an FR 10 schedule of reinforcement. In the writer's opinion, a relevant difference between the two studies was the schedule of reinforcement. The FR schedule used in the latter study provided a more sensitive measure of the willingness to work for food than did the VI schedule used in the former study, since in ratio schedules reinforcement is response-dependent.

However, Harris and Heistad (1970). in demonstrating the estrus-inhibition of hunger, used food-deprived rats. There is the possibility that food deprivation modified the effects of reproductive hormones on feeding. It is known that sufficiently severe malnutrition inhibits the secretion of hormones maintaining the estrous cycle

\footnotetext{
*The author wishes to thank George Collier of Rutgers-The State University for the liquid food dispenser and schedule control apparatus used in Experiment III.

$\div$ Requests for reprints can be sent to Wilmar A. Jennings, Psychology Department. Howard University. Washington. D.C. 20001.
}

(Leathem, 1961). If one could demonstrate the inhibitory effect of estrus on the willingness of the rat to barpress for food in a rat on ad lib feeding, such an experiment would provide a preparation easier to interpret. The third experiment in the present study made such an attempt.

In addition to the inhibitory effects of estrogen on caloric intake (Aschkenasy-Lelu \& Aschkenasy, 1959; Wade \& Zucker, 1970), estrogen and progesterone jointly affect the palatability of solutions (Zucker, 1969: Wade \& Zucker, 1969). The latter-mentioned studies showed that estrogen and progesterone injected into ovariectomized rats increased saccharin preference and decreased quinine preference. Based on these findings, it seemed reasonable to predict that less preferred caloric solutions would show a greater inhibition of intake in estrus than would more preferred solutions. This hypothesis was tested in the first two experiments reported.

\section{EXPERIMENT I}

Three sugars in solution, differing in preference (Richter \& Campbell, 1940), were chosen for study: sucrose, lactose, and a mixture of sucrose and lactose. The concentrations and caloric values were held constant across solutions.

\section{Method}

\section{Animals}

Twelve female albino Sprague-Dawley rats from Sprague-Dawley, Inc. (born in 1969) were studied: they were 104 days of age at the start of testing.

\section{Procedure}

The animals were individually housed in cages that were $22.5 \mathrm{~cm}$ long, $17.5 \mathrm{~cm}$ high. and $17.5 \mathrm{~cm}$ wide, and were given ad lib access to $\mathrm{HOH}$ and Purina Chow. They were maintained on an alternating light-dark cycle of $12 \mathrm{~h}$ of light and $12 \mathrm{~h}$ of 

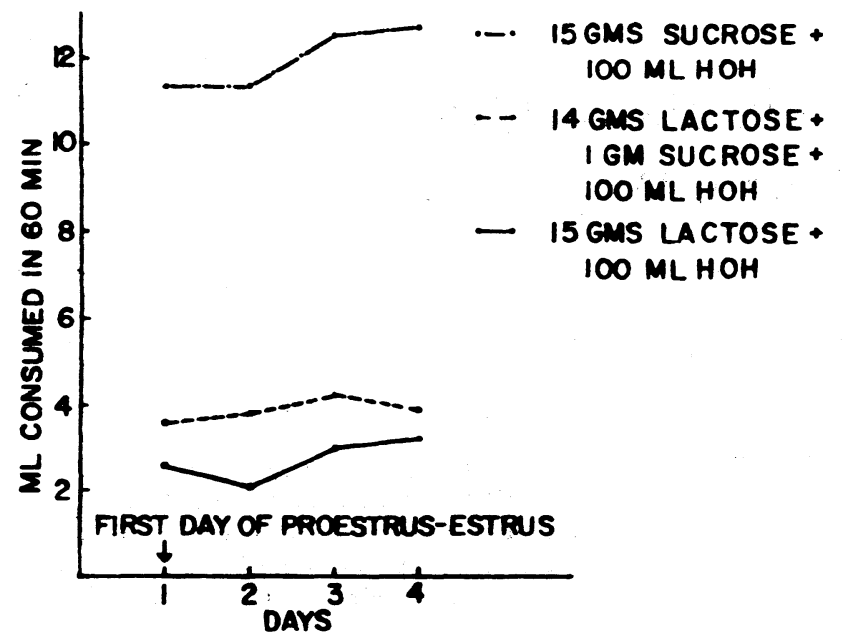

Fig. 1. Amount of solution consumed per hour as a function of kind of sugar and the estrous cycle.

dark, with the dark phase beginning at 9:00 p.m. During the last $2 \mathrm{~h}$ of the light phase, the rats were weighed and vaginal smears were measured. Following this procedure, the behavior measure (milliliters consumed from a single tube) was recorded.

Single-tube intake. Each rat was given $1 \mathrm{~h}$ of exposure to a solution. Three kinds of solutions were used: (1) sucrose (S) $-15 \mathrm{~g}$ of sucrose and $100 \mathrm{ml}$ of $\mathrm{HOH}$; (2) lactose (L)-15 g of lactose and $100 \mathrm{ml}$ of $\mathrm{HOH}$; and (3) sucrose-lactose (S-L)-14 g of lactose, $1 \mathrm{~g}$ of sucrose, and $100 \mathrm{ml}$ of $\mathrm{HOH}$. The solutions were mixed daily, $24 \mathrm{~h}$ before consumption. Intake was measured to the nearest milliliter.

Temporal order-sequence. A rat was given daily access to a solution for 15 days; following this, the rat was given access to a different kind of solution, and similarly, access to a third solution for a final 15 days. The order of solutions varied across animals -3 ! orders of the three kinds of solutions were used, and two rats were randomly assigned to each order. The 15-day period of exposure to one kind of solution was sufficiently long to contain approximately three estrous cycles.

\section{Results}

\section{Variables}

Three independent variables were used: (1) the kind of solution (S, L, and S-L); (2) the temporal order sequence of the solution (S, L, S-L; S, S-L, L; etc.); and (3) the estrous cycle. The third-mentioned variable was represented by a 4-day sequence, with the first day denoted by the marked reduction in leucocytes in the vaginal smear, characteristic of the beginning of proestrus. The dependent variable was represented by the $\bar{X}$ of all readings taken on the same day of the estrous cycle: e.g., the $\bar{X}$ of all readings taken on the first day of the marked reduction of leucocytes in the smear, the $\overline{\mathrm{X}}$ of all readings taken on the day following the first day of the reduction in leucocytes, etc. The 15-day period of access to a solution started at different points in the estrous cycle for different rats.

\section{Data}

The results were analyzed with a three-variable analysis of variance. As shown in Fig. 1, the estrous cycle produced a modest, but nevertheless significant, effect $(F=5.730 ; d f=3 / 18 ; p<.01)$. The lowest intake occurred in proestrus-estrus (the first 2 days of the 4-day sequence). As expected, the kind of solution produced a marked effect $(F=135.393 ; \mathrm{df}=2 / 12 ; \mathrm{p}<.001)$. However, the Kind of Solution by Estrous Cycle interaction needed to support the predicted differential effects of the estrous cycle on the intake of solutions differing in preference was not obtained $(\mathrm{F}=1.045 ; \mathrm{df}=$ 6/36). An interaction between the temporal order sequence and the kind of solution was obtained $(\mathrm{F}=$ 9.189; $\mathrm{df}=10 / 12 ; \mathrm{p}<.001)$.

\section{EXPERIMENT II}

The rationale for Experiment II was similar to that for Experiment $I$ in that solutions differing in taste preference were used. However, additional dimensions studied included: (1) a specific nutrient vs a balanced diet, and (2) caloric density of the food. Three solutions were used: (1) sucrose (11\% by weight), (2) evaporated whole milk (Carnation), and (3) evaporated nonfat milk (Carnation). The solutions were similar in tonicity.

\section{Method}

The method in the second experiment was identical to the method used in the first experiment, with the exception of the following modifications. Twelve female albino rats from Sprague-Dawley, Inc. (born in 1969) were studied; they were 90 days of age at the start of testing. The sucrose solution was mixed $24 \mathrm{~h}$ in advance of testing; the milk (in cans) was opened at the time of testing.

\section{Results}

The results of Experiment II are shown in Fig. 2. As was the case in Experiment I, the estrous cycle produced a significant, but modest, effect $(F=6.650 ; \mathrm{df}=3 / 18$; $\mathrm{p}<.01$ ). Intake was lower in the first 2 days of the

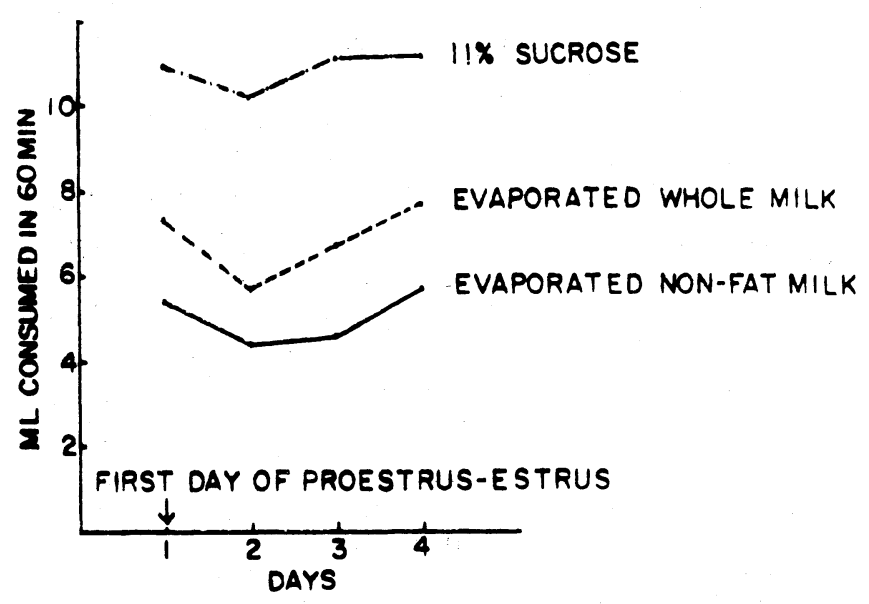

Fig. 2. Amount of solution consumed per hour as a function of kind of solution (sucrose, whole milk, or nonfat milk), and the estrous cycle. 
4-day period, with the second day showing the lowest intake of the 4 days. The differences in intake across the foods were significant $(F=29.796 ; \mathrm{df}=2 / 12 ; \mathrm{p}<.001)$. And, as in the case of Experiment I, the estrous cycle did not interact with the kind of solution: $\mathrm{F}=.517$; $\mathrm{df}=$ 6/36. But, unlike Experiment I, the Temporal Order by Sequence interaction with the kind of solution was not significant.

\section{EXPERIMENT III}

Experiment III examined a different measure of motivation from that measured in the first two experiments, namely, the willingness of the rat to work for an incentive. In the third experiment, the solutions used as reinforcers were identical to those used in Experiment II. Animals on ad lib feeding were used.

\section{Method}

\section{Subjects}

Thirty-six female rats were studied. The rats, born in 1971, were albino rats from ARS/Sprague-Dawley. Ages at the start of testing ranged between 90 and 308 days of age (depending on the replication).

\section{Apparatus}

The rats were tested in Skinner boxes consisting of modified Hoeltge cages with the same dimensions as the home cages (22.5 cm long, $17.5 \mathrm{~cm}$ high, and $17.5 \mathrm{~cm}$ wide). Inserted in the cage was a "T-shaped" bar located $9 \mathrm{~cm}$ above the floor of the cage; the criterion barpress force was $30 \mathrm{~g}$. The liquid-food magazine was located on the floor of the cage; it was constructed of acrylic (Plexiglas) and consisted of a cup, which held $1 \mathrm{ml}$ of solution, and shield, which prevented the rat from licking solution from the delivery tube. A "run-off" tunnel near the top of the cup permitted the collection of unconsumed liquid. The bar and syringe-pump device for delivering reinforcers was similar to those used by Collier, Vogel, and Rega (1966); they were manufactured by BCS Machine and Manufacturing Corp. The reinforcer volume was $.2 \mathrm{ml}$.

\section{Procedure}

Maintenance procedures in Experiment III were identical to those used in Experiments $I$ and II, with the exception that the testing period took longer -the weighing of rats, classification of smears, and Skinner box testing took place during the last $3 \mathrm{~h}$ of the light phase. A rat experienced only one kind of solution. The animals were tested in replications of 6 to 8 animals per replication. An attempt was made to represent the six experimental conditions (delineated below) in each of the replications, since the replications differed in both time of the year and age of animals. Animals showing prolonged pseudopregnancies, prolonged estrus, or irregular estrous cycles were not used in the analysis of data.

Skinner box testing. The rats were assigned, six per group, to a factorial covariation of three kinds of solutions (sucrose, whole milk, and nonfat milk, as described above in greater detail), and two different points during the estrous cycle at which testing began. More specifically, half of the rats began a behavioral session on the first day of proestrus-estrus (as denoted by a marked reduction in leucocytes); and half of the rats began testing 2 days after the first day of proestrusestrus.

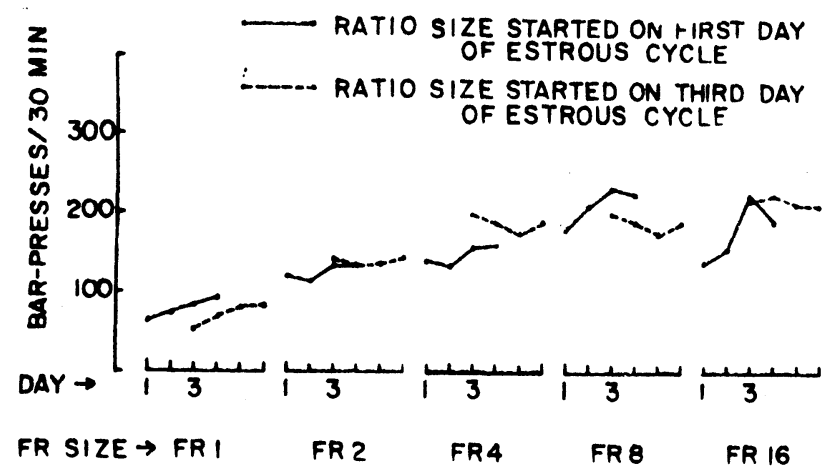

Fig. 3. Barpresses per $\mathbf{3 0} \mathrm{min}$ as a function of fixed-ratio size and when in the estrous cycle a fixed ratio was started.

The rats were exposed sequentially to the following order of reinforcement conditions: magazine training, FR 1, FR 2, FR 4, FR 8, FR 16, FR 32, FR 64, and FR 128. The rats were exposed to one of the above-mentioned schedules for one estrous cycle in duration. If a rat failed to achieve at least one reinforcer during an estrous cycle by completing the required ratio run, the rat was withdrawn from the experiment. All sessions were $30 \mathrm{~min}$ in length. All of the rats completed FR 16. Magazine training was done with an FI 60-sec schedule. When the rat was placed in the Skinner box, she encountered $1 \mathrm{ml}$ of food in the magazine but thereafter, within a session, reinforcers were contingent on the completion of a ratio run. Only 2 of the 36 rats required shaping of the barpress response. After they began to emit criterion responses, they were continued on FR 1 until they had completed an estrous cycle; thereafter, they experienced reinforcement conditions identical to those of the rats that did not require shaping. There was no noticeable accumulation of unconsumed food after magazine training was completed.

\section{Results}

The number of barpresses per $30 \mathrm{~min}$ was examined with reference to four independent variables: (1) kind of food (sucrose, whole milk, and nonfat milk); (2) fixed-ratio size (FR 1, 2, 4, 8, and 16); (3) the estrous cycle (starting a reinforcement schedule on the first day of proestrus-estrus or 2 days later); and (4) 4 consecutive days (the first 4 days on a particular schedule). Seven of the 36 rats on one of the ratio sizes showed only a 3-day estrous cycle. For such animals, the $\bar{X}$ of the data from the other animals in the particular condition (defined by kind of food, starting point in the estrous cycle, FR size, and day) containing the animal was substituted for the missing data. Condition averages based on the above-mentioned procedure were plotted in Fig. 3.

Because of the problem presented for a valid statistical analysis of the existence of missing data, an analysis of variance was performed using just the first 3 days of barpressing on a particular FR schedule. A significant interaction was found between days and when in the estrous cycle a particular schedule was started $(F=8.582 ; \mathrm{df}=2 / 60 ; \mathrm{p}<.001)$. As shown in Fig. 3, animals started 2 days after the beginning of proestrus-estrus on the first day of an FR schedule barpressed at a higher rate than rats started on the first 
day of proestrus-estrus. Additionally, the rats in the former group tended to decline over days; but the animals in the latter group increased over days. Such an interaction supports the inhibitory effect of proestrus-estrus on the motivation of feed. The above-mentioned effects were more evident in the higher FR sizes, an observation supported by a significant three-way interaction between FR size, days, and when in the estrous cycle an FR size was started: $F=2.586$; df $=8 / 240 ; p<.025$. It is reasonable that as the work requirement for a reinforcer increases, the inhibitory effect of estrus becomes more salient.

Significant main effects were found for FR size ( $F=$ $15.835 ; \mathrm{df}=4 / 120 ; \mathrm{p}<.001)$ and the kind of solution $(\mathrm{F}=12.012 ; \mathrm{df}=2 / 30 ; \mathrm{p}<.001)$. The $\overline{\mathrm{X}}$ barpress rate for sucrose was 104 barpresses per $30 \mathrm{~min}$; for whole milk, 76; and for nonfat milk, 42 .

As was true in the first two experiments, the kind of solution did not interact with the estrous cycle-the three-way interaction between days, kind of solution, and when in the estrous cycle a schedule began was not significant $(F=.262 ; \mathrm{df}=4 / 60)$; neither was the four-way interaction of the independent variables significant $(F=.493 ; \mathrm{df}=16 / 240)$.

\section{DISCUSSION}

The data support the hypothesis that the hormonal state characteristic of estrus inhibits the motivation to feed. The present study adds further evidence to a growing literature (e.g., Brobeck, Wheatland, \& Strominger, 1947; Harris \& Heistad, 1970), which shows that the estrous cycle affects two basic measures of the motivation to feed in the same way: consummatory behavior as measured by caloric intake and the willingness of the rat to work for food. The data contribute to the existing literature the following information: (1) a food as highly palatable to rats as sucrose shows an inhibition of intake in estrus, just as does the typical stock diet when a 1 -h intake measure is used; and (2) an estrus inhibition of barpressing can be demonstrated in an animal that is not food deprived.

The study failed to demonstrate that less preferred foods are inhibited in estrus to a greater extent than more preferred foods. Possibly, a greater variation between foods in preference than the variation used in the present study (from sucrose to lactose) might be needed to demonstrate such an effect.

\section{REFERENCES}

Aschkenasy-Lelu, P., \& Aschkenasy, A. Effects of androgens and oestrogens on the metabolism of proteins and the growth of tissues. In G. H. Bourne (Ed.), World review of nutrition and dietetics. London: Pitman, 1959. Pp. 33-55.

Brobeck, J. R., Wheatland, M., \& Strominger, J. L. Variations in regulation of energy exchange associated with estrus, diestrus and pseudopregnancy in rats. Endocrinology, 1947, 40, 65-72.

Collier, G., Vogel, J., \& Rega, F. Two-bar preference. Psychonomic Science, 1966, 6, 203-204.

Harris, W. C., \& Heistad, G. T. Food-reinforced responding in rats during estrus. Journal of Comparative \& Physiological Psychology, 1970, 70, 206-212.

Hodos, W., \& Valenstein, E. S. Motivational variables affecting the rate of behavior maintained by intracranial stimulation. Journal of Comparative \& Physiological Psychology, 1960, 53, 502-508.

Leathem, J. H. Nutritional effects on endocrine secretions. In W. C. Young (Ed.), Sex and internal secretions. Baltimore: Williams \& Wilkins, 1961. Pp. 666-704.

Miller, N. E., Bailey, C. J., \& Stevenson, J. A. F. Decreased "hunger" but incresed food intake resulting from hypothalamic lesions. Science, 1950, 112, 256-259.

Richter, C. P., \& Campbell, K. H. Taste thresholds and taste preferences of rats for five common sugars. Journal of Nutrition, 1940, 20, 31-46.

Wade, G. N., \& Zucker, I. Hormonal modulation of responsiveness to an aversive taste stimulus in rats. Physiology \& Behavior, 1969, 5, 269-273.

Wade, G. N., \& Zucker, I. Modulation of food intake and locomotor activity in female rats by diencephaalic hormone implants. Journal of Comparative \& Physiological Psychology, $1970,72,328-336$.

Zucker, I. Hormonal determinants of sex differences in saccharin preference, food intake and body weight. Physiology \& Behavior, 1969, 4, 595-602.

(Received for publication August 20, 1973; Accepted August 27, 1973.) 